\title{
Study of renal function test in asphyxiated newborns and their outcome
}

\author{
Murmu M.C. ${ }^{1}$, Ghosh B. ${ }^{2}$, Satpathy S.K. ${ }^{3}$ \\ ${ }^{1}$ Dr. Mangal Charan Murmu, Assistant Professor, ${ }^{2}$ Dr. Bhabatosh Ghosh, Postgraduate Resident, ${ }^{3}$ Dr. Saroj Kumar \\ Satpathy, Professor and Head, all authors are affiliated with Department of Pediatrics, S.C.B. Medical College \& \\ Hospital, Cuttack, India
}

Address for correspondence: Dr. Mangal Charan Murmu, E-Mail: mangal74murmu@yahoo.co.in

\begin{abstract}
Introduction: There is a high incidence of acute kidney injury (AKI) among asphyxiated term. AKI manifests by changes in urine output and blood chemistries \& can have serious clinical consequences. Oliguria has been reported in higher number of neonates affecting nearly 25\%- 70\% babies. Methodology: This study was undertaken to study renal failure in asphyxiated neonates. This is a prospective case controlled study done over a period of two years. Various clinical, biochemical and radiographic parameters pertaining to renal injury among asphyxiated neonates were studied. Results: About 64 asphyxiated newborns were studied. Majority (53.12\%) was term weighing between 2.5-3 kg \& most of them were in HIE-2 grade (43.75\%). Oliguria was mostly noted among HIE - $3(31.57 \%)$. Birth asphyxia and subsequent acute renal failure was more in babies delivered vaginally. Biochemical parameters also showed correlation with the severity of asphyxia. Premature babies were more prone to develop renal failure secondary to asphyxia. Mortality was directly related to severity of perinatal asphyxia and presence of oliguria. Conclusion: The incidence of acute renal failure due to perinatal asphyxia was high. Incidence with oliguria was high in severe asphyxia. Prevention of asphyxia \& prompt management of morbidities like ARF can improve the outcome of perinatal asphyxia.
\end{abstract}

Keywords: Acute renal failure, Asphyxia, Oliguria

\section{Introduction}

Perinatal asphyxia is defined by the world health organization (WHO) as "Failure to initiate and sustain breathing at birth". It is an insult to the fetus/ newborn due to hypoxia and/or ischemia to various organs of sufficient magnitude and duration to produce deranged function and/or biochemical changes. There is a high incidence of acute kidney injury (AKI) among asphyxiated term infants [1,2]. The presence of perinatal asphyxia and its severity appears to correlate with increasing incidence of AKI [1,3]. Asphyxia is an important cause of acute kidney injury (AKI) and transient kidney impairment particularly in the first five days of birth [4]. Hypoxia and ischemia can cause damage to almost every tissue and organ of the body and various target organs involved have been reported

Manuscript received: $02^{\text {nd }}$ April 2017

Reviewed: $10^{\text {th }}$ April 2017

Author Corrected: $18^{\text {th }}$ April 2017

Accepted for Publication: $26^{\text {th }}$ April 2017 to be kidneys in $50 \%$, central nervous system in $28 \%$, cardiovascular system in $25 \%$ and lungs in $23 \%$ cases [5].

Acute Kidney injury manifests by changes in urine output and blood chemistries \& can have serious clinical consequences [6]. Oliguria has been reported in higher number of neonates affecting nearly $25 \%-70 \%$ babies [7]. Early recognition of renal failure is important in babies with Hypoxic Ischemic Encephalopathy (HIE) is vital.

This study is undertaken to study renal failure in asphyxiated neonates.

\section{Aims \& Objectives}

To know the incidence of acute renal failure in asphyxiated newborn. To correlate the severity of acute renal failure with grade of HIE. 


\section{Materials and Methods}

This is a prospective case controlled study in Department of Pediatrics in close association with Department of Obstetrics and Gynaecology, S.C.B. Medical College and Hospital, Cuttack over a period of two years from study September 2014 to August 2016. Total case studied is 64 .

Inclusion criteria: Asphyxiated babies received from labour room and operation theatre with an Apgar score [8] 7 or less at 5 minutes and received within $24 \mathrm{hrs}$ of birth \& those babies who required immediate neonatal resuscitation including bag and mask ventilation or intubations. Abnormal neurological examination including the presence of any two or more of the following i) alteration of muscle tone either hypotonia/ hypertonia, 2) Abnormal neonatal reflexes including Moro, rooting and sucking, 3) Failure to arouse the infant even after vigorous stimulation, 4) Presence of convulsion. All neonates with HIE included in this study were classified according to Sarnat and Sarnat classification. The gestational age was assessed by Dubowitz criteria [9]. All the babies with birth asphyxia were clinically examined on admission and repeated at $6 \mathrm{hr}, 12 \mathrm{hr}, 24 \mathrm{hr}, 48-72 \mathrm{hrs}$ till 1 week or date of discharge.

The criteria for diagnosing a case to be of renal failure as Urine output $<0.5 \mathrm{ml} / \mathrm{kg} / \mathrm{hr}$, Blood urea $>40 \mathrm{mg} / \mathrm{dl}$, Serum creatinine $>1.5 \mathrm{mg} / \mathrm{dl}$, Presence of significant hematuria and / or proteinuria on routine and microscopic examination[1]. These criteria were implemented on day 3 of life and if 3 of the 4 criteria were present the case was picked up for study.

Exclusion criteria: An USG of abdomen and pelvis for KUB was done as and when the condition of the baby stabilised to rule out any congenital anomaly of urinary system .baby with congenital kidney anomaly were not included in study.

Renal function parameters such as blood urea, serum creatinine, electrolytes, urinary sodium and creatinine were monitored initially within $24 \mathrm{hrs}$ of birth and then on day 3 of life. After 3 days those babies having abnormal renal function had their laboratory parameters monitored every alternate day till discharge. Neonates who were diagnosed to be suffering from acute renal failure were managed as per department protocol. EGG, calculation of fractional excretion of sodium (FeNa) were done as and when required. Every fortnightly a non asphyxiated baby with no other confounding factor believed to alter renal function, such as RDS, NEC, septicemia or major congenital anomaly was picked up to serve as control.

Neonates with renal failure were followed up to 6 months with serial biochemical and radiological evaluation. All the neonates with incipient renal failure were initially checked for bladder retention and if bladder was found to be empty clinically, fluid challenge followed by a single dose of Frusemide in a dose of $1 \mathrm{mg} / \mathrm{kg} \mathrm{I.V}$. was given and if still no urination occurred the patient was monitored presumptively waiting for biochemical report.

Serum creatinine was determined by photometric determination of creatinine based Jaffe kinetic method with deproteinisation. Serum urea determination was clone by photometric determination according to urease GLDH metod. Serum and urinary electrolytes were estimated by using chloride kit (Thiocyanate method), Elyte 2 kit (Na \& K colorimeter). The ultrasonographic examination performed in the study was done using gray scale real time machine (Nebula 402) employing a 5 to $7 \mathrm{MHz}$ transducer. All the cases were studied with the help of direct contact. All the ultrasonography were done in the department of radiodiagnosis.

All the details of the case was recorded in the proforma and analysed. The proforma included details of the baby, HIE grading [3,4,5] investigations including serum creatinine, blood urea, urine routine microscopy, serum and urinary electrolytes, treatment received and findings on imaging study.

Observation: Total number of newborn developing oliguria and / or increase in creatinine value in first 72 hours were 170 (59.44\%). The number of patients recovering after bolus IV normal saline followed by intravenous frusemide if required is $106(62.35 \%)$ cases. So the number of cases taken up as study group were 64 . 
Figure -1: Newborn Received From O\&G In Asphyxiated Condition And Developing Acute Renal Failure.

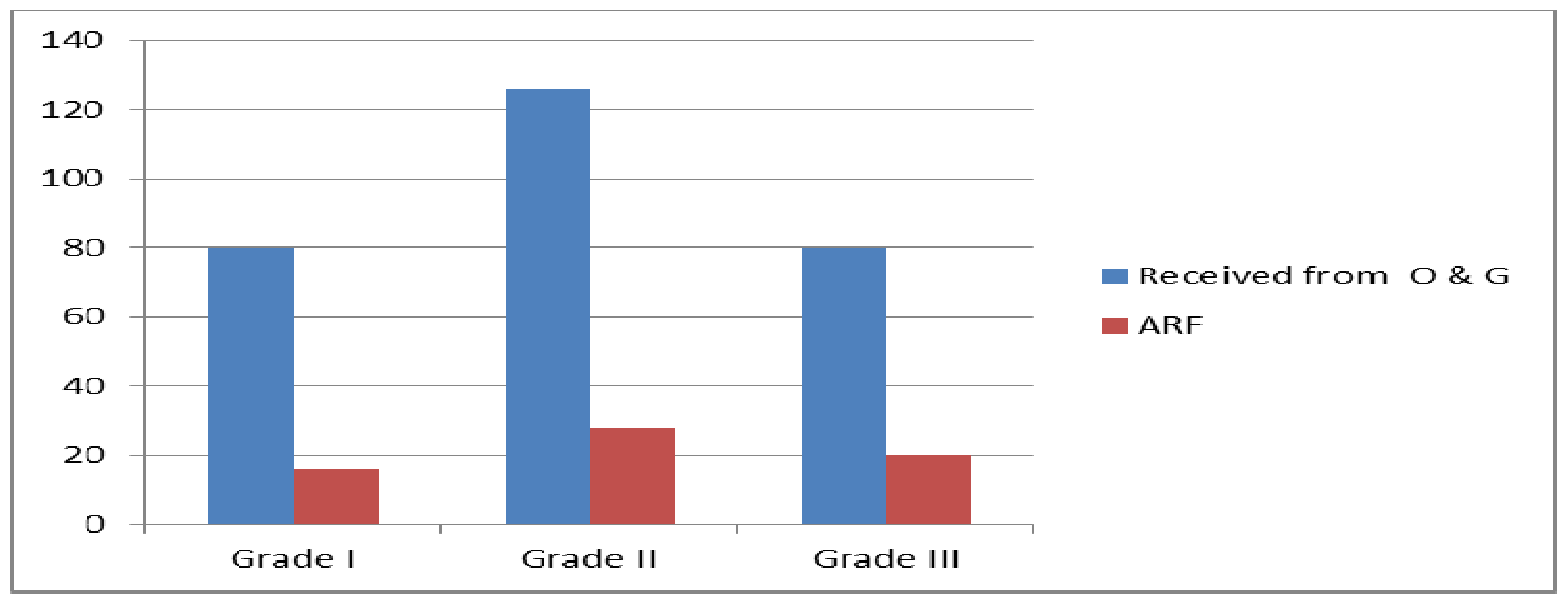

About $20 \%$ of babies with HIE Grade I developed ARF, whereas $22.22 \%$ with HIE-II \& $25 \%$ with HIE-III developed ARF

Figure-2: Number Of Control And Asphyxiated Newborn In Both Study Group According To Sex

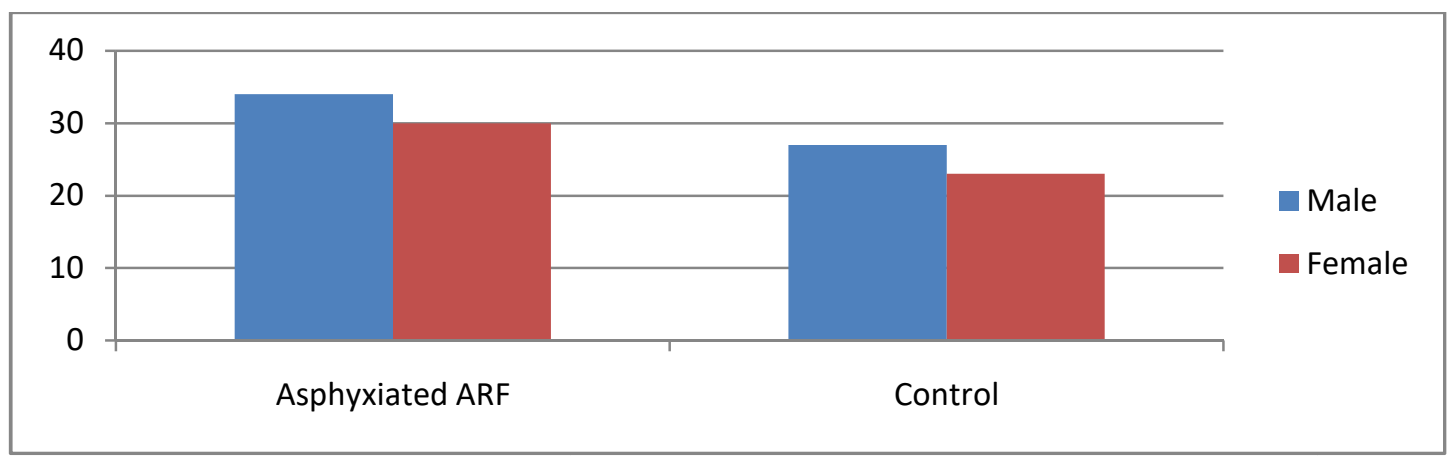

About $53.13 \%$ of asphyxiated babues with ARF \& 54\% of control were male .

Table-1: Distribution of study group according to gestational age

\begin{tabular}{|c|c|c|c|}
\hline \multirow{2}{*}{ Sl. No. } & \multirow{2}{*}{$\begin{array}{c}\text { Gestational } \\
\text { age in week }\end{array}$} & No. & Asphyxiated ARF \\
\cline { 2 - 4 } & $28-32$ & 10 & $15 \cdot 62$ \\
\hline 1 & $33-37$ & 14 & 21.87 \\
\hline 3 & Term & 40 & $62 \cdot 50$ \\
\hline
\end{tabular}

The table clearly depicts that the term neonates had the highest incidence of acute renal failure due to perinatal asphyxia.

Table-2: Distribution of neonates developing Oliguria due to ARF with HIE grading

\begin{tabular}{|c|c|c|c|c|c|}
\hline Sl. No. & Oliguria & HIE-1 & HIE-2 & HIE-3 & TOTAL \\
\hline 1 & Number of neonates & 17 & 28 & 19 & 64 \\
\hline 2 & Oliguria present & 0 & 5 & 6 & 11 \\
\hline 3 & Percentage & 0 & 17.85 & 31.57 & 17.18 \\
\hline
\end{tabular}

None of the HIE - 1 babies developed oliguria whereas $17.85 \%$ of HIE -II \& $31.57 \%$ of HIE-III babies developed oliguria. 
Table-3: Mean value of serum creatinine blood urea in different group of gestational age on day 3.

\begin{tabular}{|c|c|c|c|}
\hline Sl. No. & Gestational age in Weeks & S. Creatinine $\mathbf{~} \mathbf{~ m g / d l}$ & Blood Urea in mg/dl \\
\hline 1 & $28-32$ & 2.02 & 48.11 \\
\hline 2 & $33-37$ & 1.43 & 43.93 \\
\hline 3 & Term & 1.31 & 43.03 \\
\hline
\end{tabular}

The serum creatinine values in preterm asphyxiated babies was higher than in term babies the serum creatinine values in term babies. The same trend has been reflected in the values of blood urea.

\section{Figure-3Development Of Acute Renal Failure In Relation To Mode Of Delivery}

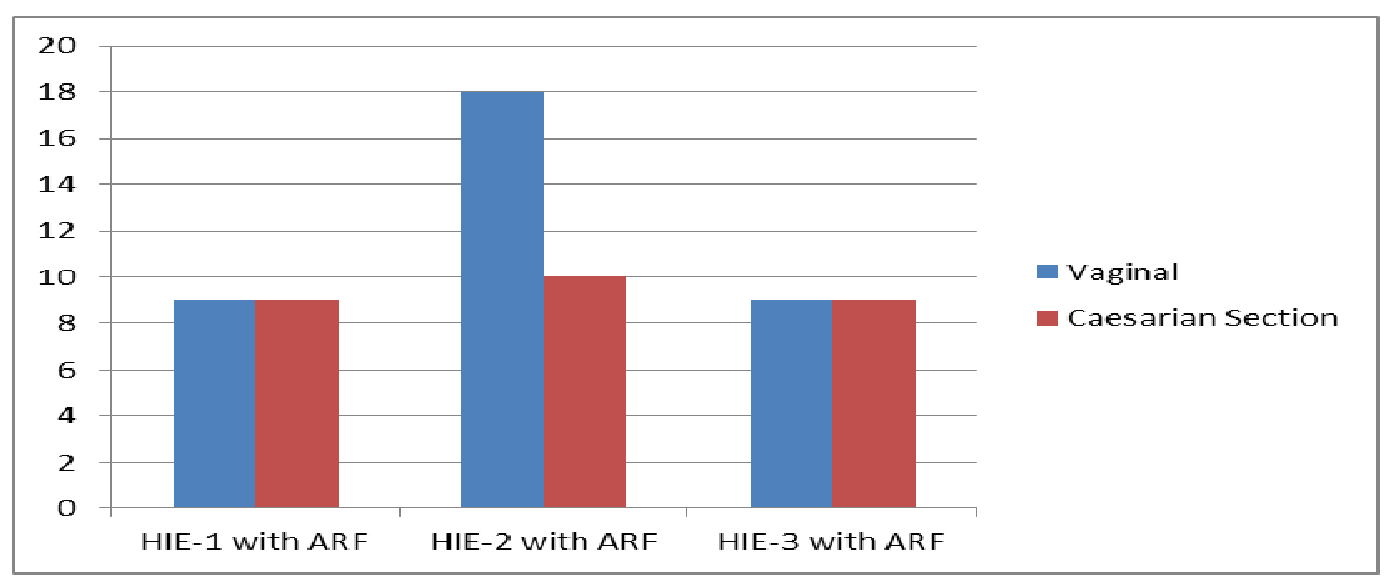

Majority of the babies with HIE-II were delivered by vaginal route

Table-4: Renal ParametersIn Different Grades of HIE

\begin{tabular}{|c|c|c|c|c|c|c|c|}
\hline $\begin{array}{c}\text { Sl. } \\
\text { No. }\end{array}$ & $\begin{array}{c}\text { HIE } \\
\text { grade }\end{array}$ & $\begin{array}{c}\text { S. } \\
\text { creatinine } \\
\text { in } \mathbf{~ m g / d l}\end{array}$ & $\begin{array}{c}\text { Blood } \\
\text { urea in } \\
\mathbf{m g / d l}\end{array}$ & proteinuria & hematuria & $\begin{array}{c}\text { Both } \\
\text { proteinuria } \\
\text { \& } \\
\text { hematuria }\end{array}$ & FENA \\
\hline 1 & 1 & 1.47 & 42.1 & 9 & 5 & 2 & 1.38 \\
\hline 2 & 2 & 1.54 & 43.2 & 9 & 13 & 6 & 1.40 \\
\hline 3 & 3 & 1.91 & 45.6 & 3 & 7 & 10 & 1.62 \\
\hline
\end{tabular}

Serucreatinine, blood urea \& FENA was high amog babies with HIE-III.

Table-5: Mortality association with HIE grade in neonates developing ARF

\begin{tabular}{|l|l|l|l|l|}
\hline Sl. No. & Grade of HIE & No. of neonates & Death & Percentage \\
\hline 1 & 1 & 16 & 1 & $6.25 \%$ \\
\hline 2 & 2 & 28 & 3 & $10.7 \%$ \\
\hline 3 & 3 & 20 & 2 & $10 \%$ \\
\hline
\end{tabular}

Death rate of neonates developing ARF due to HIE- 2 was $10.7 \%$. The death rate among the HIE - 3 was $10 \%$.

Table-6: Value of fena (frational excretion of sodium) on day 3 in relation to gestational age

\begin{tabular}{|l|l|l|}
\hline Sl. No. & Gestational age in weeks & Value of FeNa \\
\hline 1 & $28-32$ & 1.56 \\
\hline 2 & $33-37$ & 1.2 \\
\hline 3 & Term & 1.13 \\
\hline
\end{tabular}


The table shows the value of FeNa in relation to gestational age it depicts the values in preterm to be higher than in term neonates. The term babies had a mean value of 1.13 .

\section{Table-7: Distribution of mortality associated with oliguria}

\begin{tabular}{|l|l|l|l|l|l|l|}
\hline Sl. No. & Oliguria & Death & Percentage & \multicolumn{2}{l|}{ Outcome } \\
\hline & Present & Absent & & & Recovery & Residual \\
\hline 1 & 11 & & 4 & 36 & 6 & 1 \\
\hline 2 & & 53 & 2 & 3.7 & 51 & 0 \\
\hline
\end{tabular}

The distribution shows that oliguria was present in 11 of the 64 neonates. The mortality was higher in the oliguria group. Out of 6 deaths 4 occurred in the oliguria group and 2 in non-oliguria group. The percentage of death in oliguria group was $36.3 \%$ whereas in non oliguria group was $3.7 \%$.

\section{Discussion}

This study was performed on 64 neonates who developed acute renal failure due to perinatal asphyxia. The total number of babies received from obstetrics and Gynaecology department was 286 out of which 170 (59-44\%) developed oliguria and / or increase in serum creatinine values in first 72 hours. The number of patients who recovered after bolus iv normal saline followed by intravenous frusemide if required was 106 cases. So the number of cases taken up for the study after 3 days were 64 (37.64\%).

Taking into consideration the above figures it was apparent that more than $60 \%$ of babies thought to be in renal failure, were in incipient stage and improved due to bolus IV fluid and IV Frusemide. Other studies also had recommended the criteria of giving the asphyxiated babies iv bolus NS before declaring them as having intrinsic renal failure $[8,9]$. In present study males were slightly more than the females, but were equally matched with control group.

The babies in HIE - 1 were $20 \%$, in HIE -2 were $22.22 \%$ and in HIE -3 were $25 \%$. Babies who had higher grade HIE had higher incidence of acute renal failure secondary to prenatal asphyxia. In the asphyxiated renal failure group HIE-2 were highest in number $43.75 \%$, as the highest number of babies were in HIE -2. In our study term neonates contributed $62.5 \%$ of the total test group whereas grossly premature contributed $15.62 \%$ \& near term group contributed $21.87 \%$ which was similar to other study [1]. About $17.18 \%$ of the asphyxiated newborns developed oliguria due to acute renal failure. None of the HIE-1 babies developed oliguria whereas $31.57 \%$ of the HIE -3 babies developed oliguria.
The babies in HIF-1 were equally delivered by LSCS and vaginal route, where as the babies who developed HIE-2 were delivered more by vaginal route (18) than by LSCS (10). The babies who developed HIE-3 were delivered equally by LSCS and vaginal route. From the observation it may be assumed that incidence of asphyxia was more in infants born by vaginal delivery than LSCS which was similar to other studies [10.11].

Mean serum creatinine \& blood urea values in preterm babies suffering from asphyxia were higher than in the term babies suffering from asphyxia. This inverse relationship was also noted in other studies[12,13]. The study has depicted that the serum creatinine values increase in direct proportion to severity of perinatal asphyxia. The babies in HIE 3 had the highest serum creatinine and blood urea values which was comparable to other studies $[1,8,14,15]$.

Both proteinuria and hematuria were significantly found in the severe grade of hypoxia (HIE-3) which was comparable to other studies $[1,16,17,18]$. The value of $\mathrm{FeNa}$ was found to be higher in preterm neonates and its value bear direct relationship to severity of perinatal asphyxia which was similar to other studies $[1,19]$. The mortality rate due to renal failure in HIE 2 group was found to be $10.7 \%$ and in HIE 3 group was $10 \%$. In this study it has been found that death in the oliguric group was much higher than non-oliguric group which was similar to other studies [1,9]. The mortality in neonates with oliguric renal failure was $30-50 \%$ [1,9,21,22].

\section{Conclusion}

The incidence of acute renal failure due to perinatal asphyxia was high. Incidence with oliguria was high in 
severe asphyxia. Biochemical parameters also showed correlation with the severity of asphyxia. Premature babies were more prone to develop renal failure secondary to perinatal asphyxia, implying the immaturity of premature renal system. Mortality was directly related to the severity of perinatal asphyxia and presence of oliguria. Prevention of asphyxia \& prompt management of morbidities like ARF can improve the outcome of perinatal asphyxia.

\section{Abbreviations}

AKI: Acute Kidney Injury, ARF: Acute Renal Failure, dl: deciliter, ECG: ElectroCardiogram, FeNa: Fractional Excretion of Sodium, HIE: Hypoxic Ischemic Encephalopathy, Hr: Hour, IV: Intra Venous, kg: kilogram, KUB: Kidney Urinary Bladder, LSCS: Lower Segment Cesaren Section, Mhz: MegaHertz, mg: Milligram, ml: Millilitre, RDS: Respiratory Distress Syndrome, NEC: Necrotising Enerocolitis, NS: Normal Saline, USG: UltraSonogram, WHO: World Health Organization

\section{Funding: Nil, Conflict of interest: None Permission of IRB: Yes}

\section{Reference}

1. Gupta BD, Sharma P, Bagla J, Parakh M, Soni JP.Renal failure in asphyxiated neonates.Indian Pediatr. 2005 Sep;42(9):928-34.

2. Karlowicz MG1, Adelman RD. Nonoliguric and oliguric acute renal failure in asphyxiated term neonates.PediatrNephrol. 1995 Dec;9(6):718-22.

3. Martin-Ancel Ana, Garcia Alix Alfredo, Gaya Francisco, Cabanas Fernando, Buergeros Margarita. Multiple organ involvement in perinatal asphyxia.J Pediatr. 1995;127:786-93.

4. Carter B, McNabb F. Prospective validation of a scoring system for predicting neonatal morbidity after acute perinatal asphyxia. J Pediatr.1998; 132: 619-23.

5. Perlman J, Tack E, Martin T, et al. Acute systemic organ injury in term infants after asphyxia. Am J Dis Child. 1989;143(5):617-620. doi:10.1001/archpedi.1989.02150170119037

6. Chertow GM1, Burdick E, Honour M, Bonventre JV, Bates DW.Acute kidney injury, mortality, length of stay, and costs in hospitalized patients.J Am SocNephrol. 2005 Nov;16(11):3365-70. Epub 2005 Sep 21.
7. Perlman \&, Tackle. Renal injury in the asphyxiated newborn infant: Relationship to neurogenic outcome. J Pediatr 1998; 113: 875-879

8. Task Force American College of Obstetricians and Gynecologists and The American Academy of Pediatrics. Neonatal encephalopathy and CP. Defining the pathogenesis and pathophysiology. Washington DC: ACOG, 2003.

9. Lilly Dubowitz,Daniela Ricci,EugenioMercuri; the dubowitz neurological examination of the full term newborn; mental retardation and developmental disabilities research reviews 11: 52-60 (2005).

10. Giovanni Ottonello, Angelica Dessì, Paola Neroni, Maria ElisabettaTrudu, Danila Manus, VassiliosFanos.

Acute kidney injury in neonatal age; Journal of Pediatric and Neonatal Individualized Medicine 2014;3(2):e030246; doi: 10.7363/030246.

11. Sarnat H, Sarnat M. Neonatal encaphalopathy following fetal distress. Arch Neurol. 33:695 - 705. 1976.

12. Airede A, Bello M, Weerasinghe HD. Acute renal failure in the newborn: Incidence and outcome. J Paediatr Child Health. 1997;33:246-9.

13. Mortazavi F, HosseinpourSakha S, Nejati N. Acute kidney failure in neonatal period. Iran J Kidney Dis. 2009;3:136-40.

14. Alejandro G. jenik, Josc M. CerianiCernadas, AdriancGorenstin, dose A. Ramizer, Nester Vain, Marcelo Armadons and Forge R. Ferrairs. A randomized, double blind, placebo controlled trial of the effect of prophylactic theophyline on renal function in term neonates with perinatal asphyxia. Pediatrics 2000; 105;4:P.45.

15. Pamrhi V. Mohan, Pragnya M. Pai (2000). Renal insult in Asphyxia neonatorum. Indian journal of Paediatrics 2000;37: 1102-1106

16.Finer NN, Robertson CM, Richards RT, Pinnell LE, Peters KL. Hypoxic-ischemic encephalopathy in term neonates: perinatal factors and outcome.J Pediatr. 1981 Jan;98(1):112-7.

17. Chandra S1, Ramji S, Thirupuram S. Perinatal asphyxia: multivariate analysis of risk factors in hospital births.Indian Pediatr. 1997 Mar;34(3):206-12.

18. Norman M; Assadi FK (1979). A prospective study of acute renal failure in the newborn infant. Pediatrics 63:475-480. 


\section{Original Research Article}

19. Willis F, Summers J, Minutillo C, Hritt I., Indices of renal tubular function in perinatal asphyxia. Arch Dis. Child (Fetal neonatal Ed.) 1997;77:F57-F60.

20. Chevalier RL, Campbell F, Brenbridge ANAG (1984). Prognostic factors in neonatal acute renal failure.Paediatrics 74:265-272.

21. Roberts DS, Haycoch GB, Dalton RN, Tusncer C, Tomliman P, Stimmler L, Scopes JW. Prediction of acute renal failure after birth asphyxia. Arch. Dis. Child 1990;65:1021-1028.
22. Bailie MD. Renal function and disease.ClinPerinatol 1992;19:91-92.

23. Shaffer SE, Norman ME, Renal function and renal failure in the newborn, ClinPerinatol 1989;16:199-218.

24. Tack ED1, Perlman JM, Robson AM.Renal injury in sick newborn infants: a prospective evaluation using urinary beta 2 -microglobulin concentrations.Pediatrics. 1988 Mar;81(3):432-40.

25. Mathew OP et al. Neonatal renal failure: Usefulness of diagnostic indices. Pediatr 1980;65-57.

\section{How to cite this article?}

Murmu M.C., Ghosh B., Satpathy S.K.. Study of renal function test in asphyxiated newborns and their outcome. Int J Med Res Rev 2017;5(04):405-411. doi:10.17511/ijmrr. 2017.i04.06. 